\title{
GESTÃO E PARTICIPAÇÃO ESCOLAR UMA VISÃO PARA O SUCESSO DE UMA EDUCAÇÃO EFETIVA
}

Walto Luiz da Silva

Rejane Aparecida de Oliveira

Aluno Centro Universitário

\section{RESUMO}

Este artigo sobre gestão escolar é uma revisão bibliográfica dos melhores modelos de gestão escolar, onde terá uma parceria entre a instituição e a comunidade onde ela será inserida, alunos, famílias, professores e funcionários que cooperam e que opinam para o sucesso da gestão da escola. Nesta gestão todos têm voz e visam sempre o melhor para a escola. Planejar excelência da gestão democrática e participativa na unidade escolar, trará benefícios para toda a unidade escolar, onde todos ajudam na tomada de decisão, o resultado será efetivamente positivo. Essa tarefa serve para contribuir na implementação das mudanças, ajudando a criar um clima organizacional favorável a toda a comunidade, pois todos ajudam na tomada de decisão.

\section{Palavras-Chave: Gestão Educacional, Participação, Desafios, Aprendizagem.}

\section{1- INTRODUÇÃO}

A escola tem a tarefa institucional de garantir que os alunos se tornem usuários efetivamente hábeis do conhecimento, e com isso trabalhar com uma gestão democrática e participativa ajudará a ter um ambiente escolar cada vez mais participativo, e o envolvimento de todos. Esta gestão participativa e democrática terá o envolvimento e a participação de todos na tomada de decisão. Outro ponto importante é a transparência, em que qualquer decisão tomada pela escola será do conhecimento de todos. Com esta gestão terá educandos que possam saber ler, interpretar, calcular, ter conhecimentos do conteúdo curricular, pois será para a formação plena do cidadão. Como a cada época percebe-se o aumento da população em diferentes níveis sociais, e a sua participação e a 
preocupação em tomar parte ativamente em processos que afetam os seus interesses e necessidades, aí vem esta necessidade da escola aplicar cada vez mais esta gestão democrática e participativa onde pode ser atingido todos os níveis e cada vez mais estar preocupados com a educação com qualidade.

Considera-se que a gestão democrática e participativa veio para substituir aquela gestão autoritária, com espaço sem coletividade, onde apenas o gestor/diretor decide quais os objetivos, ninguém tinha o direito de se expor, de participar das tomadas de decisões, afinal, a escola não seria o lugar onde todas as pessoas desenvolvem suas habilidades intelectuais, emocionais e sociais.

\section{2- REFERENCIAL TEÓRICO}

\section{2-1 A GESTÃo EDUCACIONAL COM UMA VISÃo DEMOCRÁTICA E PARTICIPATIVA}

Em algumas análise e estudos teóricos, elaborado por Paro (2008), Barroso (2006), dentre outros, vêm demonstrando que uma gestão democrática participativa para as instituições educacionais torna-se uma grande valorização da autonomia, que ao mesmo momento, seja incentivado uma maior participação efetiva ao pensar e agir dos grandes temas, tomada de decisão, perspectivas e problemas internos com uma visão da melhoria continua da qualidade.

É difícil de imaginar que o sucesso de uma instituição escolar possa ter resultado sem que haja a participação, comprometimento e integração de todos, desde o diretor até a equipe da limpeza, pois todos formam um corpo/equipe escolar. Toda esta atividade faz-se relevante, pois precisa ter uma equipe coesão e que seja voltada pelos interesses institucionais que é uma educação com qualidade, sempre voltada para o ensinoaprendizagem, e com o qual proporcionará um ambiente escolar de sucesso para todos os educandos.

Segundo Luck (1998), a gestão já pressupõe em si a ideia de participação, isto é, do trabalho coletivo de pessoas analisando situações, decidindo sobre seu encaminhamento e agindo sobre ela em conjunto.

Gestão é administração, é tomada de decisão, é organização, é direção. Relaciona-se com a atividades de impulsionar uma organização atingir seus objetivos, cumprir sua função, desempenhar seu papel. Constitui-se de princípios e práticas decorrentes que afirmam ou desafirmam os princípios que as geram. Esses princípios, entretanto, não são intrínsecos à gestão como a concebia a administração clássica, mas são princípios sociais, visto que a gestão da educação se destina à promoção humana. (FERREIRA, 2003,p.306) 
Para Paro (2008) a ideia de gestão sob a visão democrática visa e valoriza o desenvolvimento da instituição de uma maneira cada vez mais autônoma e participativa, pois a equipe educacional pode agir ativamente em temas que seja de maior relevância para a instituição, bem como na tomada de decisão em todas as esferas, desde o planejamento, a execução das ações propostas, e ainda em uma avaliação de reação, quando esta é pautada sob as premissas democráticas e participativas.

Precisa que o gestor passe para todos que é uma gestão democrática, mas não é aquela gestão em que todos fazem o que querem, mas sim fazer o que será bom para todos e com a participação e decisão de todos.

Essa participação e interação de todos nos mais diversos níveis de decisão e nas suas atividades, é primordial para garantir o efetivo desempenho da instituição educacional. Portanto, esta participação precisa ser delegada como um processo de interação e dinâmico, que pode ir além da tomada de decisão, isto é caracterizado como a participação efetiva e na convivência do cotidiano escolar, na procura pelos seus agentes, da vitória das dificuldades e limitações e do ótimo cumprimento da sua finalidade dentro do ambiente escolar com a finalidade da busca educacional e também uma finalidade social, por isso essa gestão participativa traz sucesso quando trabalhada de forma onde todos sabem qual o seu papel e o objetivo final da instituição.

Dentro do contexto de uma gestão educacional voltada para uma gestão democrática e participativa, existem várias formas de participar, em uma simples presença física, até mesmo assumindo responsabilidades em ações e situações. A administração cientifica preconiza-se a prática da participação em toda e qualquer atividade humana, por mais que seja da menor forma, é da grande importância para o sucesso da instituição, pois o que vai prevalecer no final será a soma de todos e o sucesso da instituição com o ensino aprendizagem dos educandos. Em uma das oportunidades escolares mais comum no que se diz participação, é dos professores, pois eles estão na linha de frente desta gestão onde o processo educacional está com eles, e por isso se deve a motivação e a educação continuada para os mesmos, no sentido de que eles serão os corresponsáveis para um ensino aprendizado de sucesso. A participação efetiva de todos da comunidade escolar, coletivamente organizadas, discutem e analisam problemas didático pedagógico que vivenciam e com isso há uma interação da organização escolar, e determinam o melhor caminho para poder superar os desafios e as dificuldades que julgarem mais necessários no momento.

Barroso (2006) destaca o quanto a participação e autonomia são meios da democratização. A participação é fundamental ao método de tomada de decisão democrática para possibilitar aos envolvidos acompanharem e decidirem quais rumos da instituição educacional. Ao mesmo tempo que a instituição escolar tem a autonomia para implantar as suas políticas internas de acordo com a tomada de decisão de todo corpo escolar. 
Para Dourado (2006) a gestão democrática, como mecanismo de cooperação, participação e autonomia, é uma atividade contínua que deseja a transformação da instituição escolar e ao mesmo tempo a sociedade na qual está inserida.

\section{2-2 OS SENTIDOS, VARIAÇÕES E ALCANCE DA PARTICIPAÇÃO DEMOCRÁTICA ESCOLAR}

Em estruturas democráticas e participativa, as decisões são tomadas com todos que fazem parte da instituição de maneira compartilhada, o que presume o compartilhamento da liderança. Mas neste caso trata-se de uma liderança distribuída, ainda que sendo orientada e balizada pelo responsável da organização. (LUCK, 2010).

Dentro dos grandes desafios encontrados na gestão, a liderança é um tema chave para o gestor, em função do seu papel fundamental que representa na efetividade do time e da instituição. $O$ líder é o responsável pelo sucesso e/ou fracasso da instituição, e com isso exige muita disciplina, humildade, paciência, respeito e compromisso, pois a instituição escolar é composta dos diferentes tipos de colaboradores.

Embora a gestão seja bem falada e conhecida, este conceito de gestão/liderança precisa ser bem aplicada na comunidade escolar, onde o líder precisa estar atentos a algumas práticas que possa ajudar a ter um sucesso efetivo na comunidade escolar, aqui se diz comunidade escolar pois o objetivo será dos educandos, onde todos estão comprometidos e motivados.

- Influência sobre as pessoas, a partir de sua motivação para a atividade;

- Propósitos claros de orientação, assumidos por essas pessoas;

- Processos sociais dinâmicos, interativos e participativos;

- Modelagem de valores educacionais elevados;

- Orientação para o desenvolvimento e aprendizagem contínuos.

Podemos, pois, a partir desses componentes, conceituar liderança como sendo o processo de influência, realizado no âmbito da gestão de pessoas e de processos sociais, no sentido de mobilização de seu talento e esforças, orientado por uma visão clara e abrangente da organização em que se situa e de objetivos que deva realizar, com a perspectiva da melhoria contínua da própria organização, de seus processos e da pessoas envolvidas. (LUCK. 2010, p.35)

O desafio do gestor é trazer todos a entender qual é o seu papel na atual gestão participativa democrática, visto que o principal protagonista desta gestão é o professor e ele precisa estar aberto e preparado para se inserir nas novas tecnologias que estamos passando em tempos de revolução tecnológica para poder atender as demandas atuais do mundo pós moderno. Este professor tem um papel primordial em inovação das aulas e, principalmente auxiliar os alunos no atendimento das mídias, e tendo o papel de orientá-lo quanto a sua formação. Observa-se que não há uma reforma pedagógica e educacional sem a participação dos professores, pois esta gestão precisa cada vez ser de todos pois no final os alunos com conhecimentos será o reflexo de toda a equipe educacional. 
Lück (2009, p.16) afirma que "por excelentes que estejam os processos de gestão escolar, pouco adiantará, se ao final não produzam resultados efetivos de melhoria do ensino aprendizagem dos alunos". Portanto, nada vale um ambiente democrático escolar se ele não tiver o caráter transformador e educador dos alunos, capaz de atingir avanços no processo educacional e democrático dos participantes. Ainda, torna-se importante destacar que a comunidade escolar competente a todos os membros da escola, alunos, professores, diretores e os pais. Todos devem ser parte efetiva dessa gestão na busca do sucesso educacional de todos.

Com toda essa nova visão da gestão escolar voltada para a participação de todos, nasce novos olhares sobre a democratização da escola, extinguindo antigos entraves, como a desigualdade, discriminação, posturas centralizadoras, tudo isso na perspectiva de romper com antigos paradigmas na busca de transformar a escola em um ambiente de igualdade e oportunidades de todos para todos.

\section{2-3 A GESTÃo DEMOCTRÁtiCA SITUAdA NO CONTEXTO ATUAL ESCOLAR}

Nas atividades atuais em tempos cada vez mais globalizado e tecnológico, e dentro da esfera escolar precisa-se entender a diferenciação de Gestão Escolar e Gestão Educacional.

A Gestão Educacional demonstra uma visão mais ampla e macro de todos os órgãos superiores de ensino, suas políticas inerentes a educação. Já a Gestão Escolar está em um nível mais micro, com a visão do ambiente escolar, com as atividades daquela unidade escolar, envolvida com a gestão educativa e presume uma gestão democrática.

A possibilidade de uma administração democrática no sentido de sua articulação, na forma e conteúdo, com os interesses da sociedade como um todo, tem a ver com os fins e a natureza da coisa administrada. No caso da Administração Escolar, sua especificidade deriva, pois: a) dos objetivos que se buscam alcançar com a escola; b) da natureza do processo que envolve essa busca. Esses dois aspectos não estão de modo nenhum desvinculados um do outro. A apropriação do saber e o desenvolvimento da consciência crítica, como objetivos de uma educação transformadora, determinam (...) a própria natureza peculiar do processo pedagógico escolar; ou seja, esse processo não se constitui em mera diferenciação do processo de produção material que tem lugar na empresa, mas deriva sua especificidade de objetivos (educacionais) peculiares, objetivos estes articulados com os interesses sociais mais amplos e que são, por isso, antagônicos aos objetivos de dominação subjacentes à atividade produtiva capitalista (PARO, 1996, p.151).

Destacar na gestão escolar com visões amplas e democráticas pressupõe o permanente encanto de fins pedagógicos para que a escola e os educandos possam aspirar a sua função social com grande efetividade. E, por isso, é necessário aceitar a educação como processo de desenvolvimento da cultura humana e da escola, como instituição que provê a educação compartilhada e sistematizada 
com o envolvimento de todos. É imprescindível ter claro que ao falar em objetivos escolares, ainda mais em escola pública, eles precisam ter seu acolhimento e atendimento voltado à uma camada de pessoas/alunados que são trabalhadores, e com isso atender esta demanda.

Quando se fala em educação, é preciso ter o entendimento de como era a antes, o que avançou e está avançando ainda mais em tempos de pandemia, e o que precisamos estar mudando. E isso nos leva a uma atenção para de transformação e cada vez mais ter uma gestão participativa para que possamos estar ligados a essa nova tendência de educação tecnológica, e buscar o melhor caminho a ser trilhado. 


\section{BIBLIOGRAFIA}

BARROSO, João. O reforço da autonomia das escolas e a flexibilização da gestão escolar em Portugal. In: FERREIRA, Naura S. Carapeto (Org). Gestão democrática da educação: atuais tendências, novos desafios. $5^{\text {a }}$ ed. São Paulo: Cortez, 2006.

DOURADO, Luiz F. A escolha dos dirigentes escolares: políticas e gestão da educação no Brasil. In: FERREIRA, Naura S. Carapeto (Org.). Gestão democrática da educação: atuais tendências, novos desafios. $5^{\text {a }}$ ed. São Paulo: Cortez, 2006.

FERREIRA, Naura Carapeto. Gestão democrática da educação:

Atuais tendências, novos desafios, 4 ed., São Paulo: Cortez.2003

LACOMBE, Francisco Jose Masset. Recursos Humanos: princípios e benefícios. São Paulo: Saraiva, 205.

LUCK, Heloisa. A escola participativa: o trabalho do gestor escolar. 6 ed. Rio de Janeiro: 2002

LÜCK, Heloísa. Planejamento em orientação educacional. 17. ed. Petrópolis: Vozes, 2008.

PARO, Vitor Henrique. Administração Escolar: Introdução crítica. 15a edição. São Paulo: Cortez, 2008. 